\title{
Chemical Reactivity Descriptor for the Oxide-Electrolyte Interface in Li-Ion Batteries
}

\author{
Livia Giordano, ${ }^{*},,\|\|$ Pinar Karayaylali, ${ }^{\dagger}$ Yang Yu, ${ }^{\ddagger}$ Yu Katayama, ${ }^{\S, \perp}$ Filippo Maglia, ${ }^{\#}$ Simon Lux, ${ }^{\#}$ \\ and Yang Shao-Horn $*,+, \$ \odot$
}

${ }^{\dagger}$ Department of Mechanical Engineering, ${ }^{\ddagger}$ Department of Materials Science \& Engineering, ${ }^{\S}$ Research Laboratory of Electronics, Massachusetts Institute of Technology, 77 Massachusetts Avenue, Cambridge, Massachusetts 02139, United States

"Department of Material Science, Università di Milano-Bicocca, Via Cozzi 55, 20136 Milano, Italy

${ }^{\perp}$ Department of Energy and Hydrocarbon Chemistry, Graduate School of Engineering, Kyoto University, Kyoto 615-8510, Japan

"BMW Group, Petuelring 130, 80788 München, Germany

Supporting Information

ABSTRACT: Understanding electrochemical and chemical reactions at the electrodeelectrolyte interface is of fundamental importance for the safety and cycle life of Li-ion batteries. Positive electrode materials such as layered transition metal oxides exhibit different degrees of chemical reactivity with commonly used carbonate-based electrolytes. Here we employed density functional theory methods to compare the energetics of four different chemical reactions between ethylene carbonate (EC) and layered $\left(\mathrm{Li}_{x} \mathrm{MO}_{2}\right)$ and rocksalt $(\mathrm{MO})$ oxide surfaces. $\mathrm{EC}$ dissociation on layered oxides was found energetically more favorable than nucleophilic attack, electrophilic attack, and EC dissociation with oxygen extraction from the oxide surface. In addition, EC dissociation became energetically more favorable on the oxide surfaces with transition metal ions from left to right on the periodic table or by increasing transition metal valence in the oxides, where higher degree of EC dissociation was found as the Fermi level was lowered into the oxide $\mathrm{O} 2 p$ band.

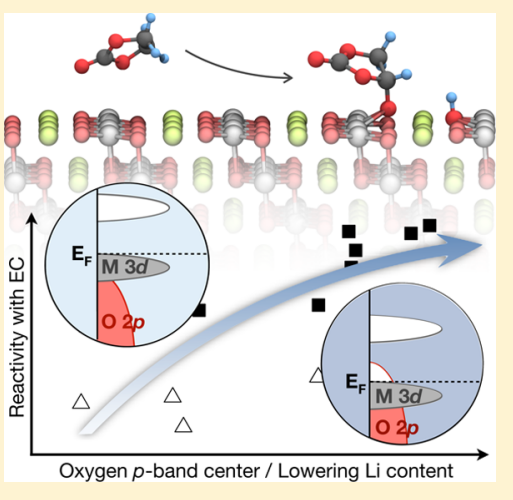

$\mathrm{L}$ ithium-ion (Li-ion) batteries nowadays represent the most $\checkmark$ used and viable technology for powering hybrid, plug-in and electric vehicles. ${ }^{1-3}$ Minimizing electrochemical and chemical parasitic reactions at the electrode-electrolyte interface (EEI) is of fundamental importance to enhance battery energy density, safety and cycle life. Commonly used carbonate-based electrolytes are not stable against the negative electrode, as the lowest unoccupied molecular orbital (LUMO) of the electrolyte is below the Fermi level of lithium or graphite, ${ }^{4-6}$ leading to the reduction of solvents and solvated ions ${ }^{4-7}$ and the formation of the solid electrolyte interphase (SEI). SEI consists of both organic, such as semicarbonates and oligomers, and inorganic species like $\mathrm{LiF}$ and $\mathrm{Li}_{2} \mathrm{CO}_{3}{ }^{8-11}$ and prevents further electrolyte decomposition. On the other hand, carbonate-based solvents (oxidation potential $\sim 6.0 \mathrm{~V}$ vs $\mathrm{Li}^{+}$/ $\mathrm{Li}^{12-14}$ ) and electrolytes (reported oxidation potential $\sim 4.7 \mathrm{~V}$ vs $\mathrm{Li}^{+} / \mathrm{Li}$ for $\mathrm{LiClO}_{4}$ in propylene carbonate $(\mathrm{PC})^{15}$ ) can be stable in the operating voltages ${ }^{16,17}$ of the positive electrodes, particularly if measured with noble metals (i.e., gold or platinum). ${ }^{4}$ However, $\mathrm{Xu}$ et al. $^{18}$ reported that $\mathrm{LiPF}_{6^{-}}$ containing dimethyl carbonate (DMC) electrolyte can be oxidized electrochemically with a lower onset potential on spinel $\mathrm{Li}_{x} \mathrm{Mn}_{2} \mathrm{O}_{4}$ compared to glass carbon $\left(\sim 6.0 \mathrm{~V}\right.$ vs $\mathrm{Li}^{+} / \mathrm{Li}$ on the latter electrode), which difference cannot be explained by greater surface area of spinel structure alone. In addition, the amount of oxidized carbon species detected on the oxide- electrolyte interface ${ }^{19-23}$ largely resulting from electrolyte decomposition, increases from cycled $\mathrm{Li}_{x} \mathrm{Mn}_{2} \mathrm{O}_{4}$ and $\mathrm{Li}_{x} \mathrm{CoO}_{2}$ to $\mathrm{Li}_{x} \mathrm{Ni}_{0.8} \mathrm{Co}_{0.2} \mathrm{O}_{2}{ }^{7,23-26}$ as measured by $\mathrm{X}$-ray photoemission spectroscopy (XPS). Moreover, replacing $\mathrm{Co}$ with $\mathrm{Ni}$ in $\mathrm{Li}_{x} \mathrm{CoO}_{2}$ leads to larger electrode impedance during cycling, $7,27,28$ which can be attributed to more resistive EEI layers. The higher reactivity of $\mathrm{LiNiO}_{2}$ is further confirmed by detection of $\mathrm{CO}_{2}$, resulting from the decomposition of the electrolyte (based on PC and ethylene carbonate (EC)/DMC mixtures with $1 \mathrm{M} \mathrm{LiN}\left(\mathrm{SO}_{2} \mathrm{CF}_{3}\right)_{2}$ as electrolytic salt) by differential electrochemical mass spectrometry (DEMS) at 4.2 $\mathrm{V}$ versus $\mathrm{Li}^{+} / \mathrm{Li}$, where no decomposition products where observed for $\mathrm{LiCoO}_{2}$ and $\mathrm{LiMn}_{2} \mathrm{O}_{4} \cdot{ }^{29}$ These observations highlight the critical role of transition metal oxides in promoting the decomposition of carbonate-based electrolytes and electrode impedance. Unfortunately, the physical origins responsible for the enhanced reactivity between oxides and carbonate-based electrolytes are not understood, which hinders the design of stable positive electrodes to improve lithium ion battery energy density, cycle life, and safety.

Here we examine the chemical reactivity of carbonate-based electrolytes with oxides. Pioneering work from Aurbach et al.

Received: June 28, 2017

Accepted: August 2, 2017

Published: August 2, 2017 
has proposed that the oxide anions at the more basic $\mathrm{LiNiO}_{2}$ surface can react with the solvent, i.e., ethylene carbonate (EC), through nucleophilic attack, followed by ring-opening and possibly starting a chain reaction toward other EC molecules. ${ }^{27}$ Theoretical $a b$ initio molecular dynamics (MD) on $\mathrm{Li}_{0.6} \mathrm{Mn}_{2} \mathrm{O}_{4}{ }^{30}$ and static simulations on $\mathrm{LiNi}_{0.5} \mathrm{Mn}_{0.3} \mathrm{Co}_{0.2} \mathrm{O}_{2}{ }^{31}$ indicated that when approaching the oxide surface the EC molecule first binds with the oxygen of the carbonyl group to the transition metal atom, which acts as a Lewis acid (electrophilic attack). Other computational studies have shown that after adsorption EC can dissociate, where a $\mathrm{C}-\mathrm{H}$ bond is broken and $\mathrm{H}$ is transferred from the solvent to the surface, forming surface hydroxyls, on the $\mathrm{Li}_{x} \mathrm{Mn}_{2} \mathrm{O}_{4}(111)(\mathrm{x}=$ $0.67,0.83,1),{ }^{32} \mathrm{Li}_{x} \mathrm{Ni}_{0.5} \mathrm{Mn}_{1.5} \mathrm{O}_{4}(\mathrm{x}=0)$ (111) and (100) surfaces. ${ }^{33}$ On $\mathrm{Li}_{0.6} \mathrm{Mn}_{2} \mathrm{O}_{4}$ (100) the dissociation is also accompanied by oxygen extraction from the surface and the formation of an oxygen vacancy. ${ }^{30}$ Moreover, on the $\mathrm{LiCoO}_{2}$ (1014) surface also EC ring opening catalyzed by $\mathrm{PF}_{6}$ anions or other EC molecules has been reported. ${ }^{34}$ In this letter, we report the energetics of these chemical reaction mechanisms previously reported for $\mathrm{EC}$ on the surface of layered $\mathrm{Li}_{x} \mathrm{MO}_{2}$ and rocksalt $\mathrm{MO}$, where the role of transition metal $\mathrm{M}(\mathrm{M}=$ $\mathrm{Mn}, \mathrm{Fe}, \mathrm{Co}$ and $\mathrm{Ni}$ ) and the amount of lithium in $\mathrm{Li}_{x} \mathrm{MO}_{2}$ are examined. EC dissociation on $\mathrm{Li}_{x} \mathrm{CoO}_{2}$ (with and without formation of oxygen vacancy) becomes energetically more favorable with decreasing lithium content, i.e., increasing cobalt oxidation state, while the energetics of the other reaction mechanisms is less sensitive to the Li-content. In contrast, EC dissociation on rocksalt $\mathrm{MO}(\mathrm{M}=\mathrm{Mn}, \mathrm{Fe}, \mathrm{Co}$ and $\mathrm{Ni})$ is energetically unfavorable, while is stabilized when changing $M$ from the left to the right of the periodic table in $\mathrm{LiMO}_{2}$. High covalency of late $3 d$ transition metal-oxygen bonds is associated with more reactive surface oxygen sites due to holes formed in the $\mathrm{O}$ states, and more reducible metal ions. ${ }^{35,36}$ We show that the greater energy of EC dissociation is correlated with the closer Fermi level to the $\mathrm{O} 2 p$ band, which is proposed as a chemical reactivity descriptor of carbonatebased electrolytes on oxide surfaces.

EC Reactivity on the $\mathrm{LiCoO}_{2}$ (10144) Surface. We first examined the energetics of previously reported reaction mechanisms for the interaction of $\mathrm{EC}$ on $\mathrm{LiCoO}_{2}$, as shown in Figures 1 and S1. The considered reaction mechanisms include nucleophilic attack from the oxide ions to the solvent carbonyl carbon atoms (Figure 1a) and alkylene carbon (Figure S2), ${ }^{27}$ electrophilic attack, where the carbonyl oxygen of EC interacts with the metal site of the oxide surface (Figure 1b), ${ }^{30,31}$ and dissociation of one $\mathrm{C}-\mathrm{H}$ bond with the formation of surface hydroxyl groups ${ }^{30,32,33}$ without (Figure 1c) and with the concomitant formation of an oxygen vacancy in the oxide ${ }^{30}$ (Figure 1d). The (1014) surface orientation was chosen for $\mathrm{LiMO}_{2}$, as it is the most stable nonpolar surface ${ }^{37}$ and allows $\mathrm{Li}$ ions intercalation, while the (100) surface orientation was selected for rocksalt MO (see Figure 2, Computational Methods, and Supporting Information for details of the surface models).

The reaction energy computed with respect to the gas phase $\mathrm{EC}$ molecule as $\Delta E=E\left({ }^{*} \mathrm{EC}\right)-E(\mathrm{EC})-E(*)$, where $E(* \mathrm{EC}), E(\mathrm{EC})$, and $E(*)$ are the DFT total energies of EC adsorbed on the surface (*EC), EC in the gas phase (EC), and of the bare surface $(*)$, is weak for all mechanisms considered on the $\mathrm{LiCoO}_{2}(10 \overline{1} 4)$ surface (Figure 1). The nucleophilic attack of EC carbon atoms for both carbonyl (Figure 1a) and alkylene carbon (Figure S2) was found to have positive reaction
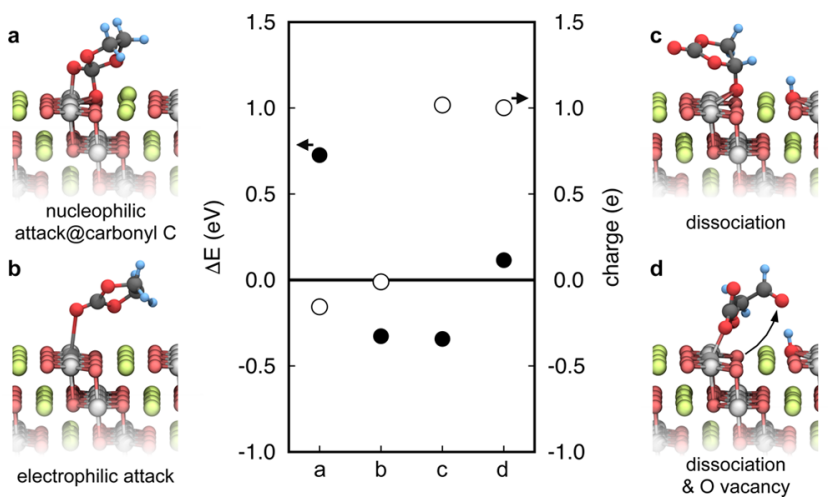

Figure 1. Reaction energy $\Delta E$ (filled circles) and charge transfer (empty circles) for ethylene carbonate (EC) adsorbed on the $\mathrm{LiCoO}_{2}$ $(10 \overline{1} 4)$ surface. The structures represent the optimized configurations for the reaction mechanisms considered: (a) nucleophilic attack ${ }^{27}$ at carbonyl carbon, (b) electrophilic attack, ${ }^{30,31}$ (c) dissociation, ${ }^{30,32,33}$ and (d) dissociation with formation of an oxygen vacancy in the oxide. ${ }^{30} \mathrm{H}$ atoms are represented in light blue, $\mathrm{C}$ in dark gray, $\mathrm{O}$ in red, $\mathrm{Li}$ in green, and $\mathrm{Co}$ in light gray. The computed charge transferred was obtained by subtracting the sum of the Bader charges in the EC molecule adsorbed on the oxide surface relative to that in vacuum. A positive charge indicates a transfer of electrons from the adsorbed EC to the oxide surface.

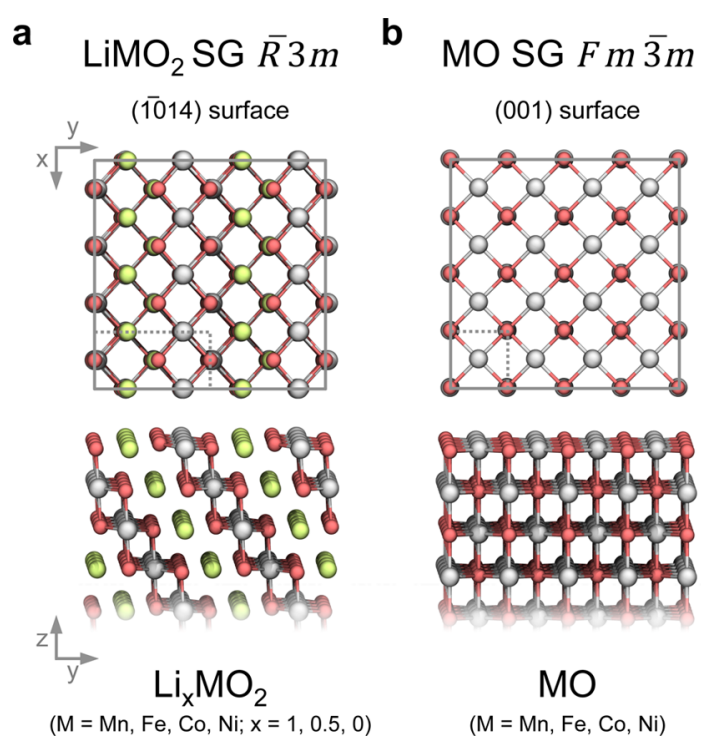

Figure 2. Top (upper panels) and side (bottom panels) view of the surface models used in this study for the adsorption of ethylene

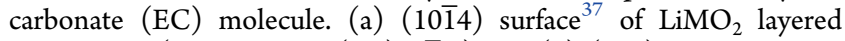
compounds (Space Group (SG) $R \overline{3} m$ ) and (b) (001) surface of MO rock-salt oxides (SG $F m \overline{3} m$ ), where oxygen atoms are in red, lithium in green, and transition metal in light gray.

energy, larger than $0.5 \mathrm{eV}$. The nucleophilic attack at the carbonyl carbon had the ring intact, having structural deformation from the formation of the additional $\mathrm{C}-\mathrm{O}$ bond with the lattice oxygen and the consequent change of hybridization of the carbon atom from $s p^{2}$ to $s p^{3}$. This configuration is characterized by considerable steric hindrance, the energetic cost of which is not completely compensated by the formation of the additional bond. The nucleophilic attack at the alkylene carbon (Figure S2) induces the opening of the ring as the lattice oxygen replaces one of the $\mathrm{C}-\mathrm{O}$ bonds in the molecule. The strong structural distortion can be one of the 
reasons beyond the large instability of this configuration. Negligible charge transfer was found for the nucleophilic attack at alkylene carbon, while the nucleophilic attack at carbonyl carbon produced a small electron transfer from the surface to the molecule (Figure 1).

Only electrophilic attack (Figure 1b) and EC dissociation producing a surface $\mathrm{OH}$ group (Figure 1c) were found to have a negative reaction energy. We should note that to assess whether these reactions can take place at the interface, the free energy of reaction should be computed and solvation effects included. However, previous calculations of EC on $\mathrm{Li}_{0.6} \mathrm{Mn}_{2} \mathrm{O}_{4}(100)$, where $\mathrm{MD}$ simulations on solvent/oxide were compared with isolated $\mathrm{EC}$ at the vacuum/oxide interface, indicated that the relative stability of the different configurations is maintained in the latter. ${ }^{30}$ The EC molecule was found largely unperturbed in the electrophilic attack configuration, physisorbed on the surface through an elongated (2.58 $\AA$ ) $\mathrm{Co}-\mathrm{O}_{\mathrm{C}}$ bond (where $\mathrm{O}_{\mathrm{C}}$ indicates the EC carbonyl oxygen atom). The electrophilic attack induced negligible charge transfer, in agreement with the physisorbed nature. EC dissociation without the formation of oxygen vacancy (Figure 1c) takes place by the following reaction: $\mathrm{C}_{3} \mathrm{O}_{3} \mathrm{H}_{4}+2 \mathrm{O}-$ $\mathrm{M}^{3+}-\mathrm{O} \rightarrow{ }^{*} \mathrm{C}_{3} \mathrm{O}_{3} \mathrm{H}_{3}{ }^{+}+{ }^{*} \mathrm{H}^{+}+2 \mathrm{O}-\mathrm{M}^{2+}-\mathrm{O}$, where ${ }^{*} \mathrm{C}_{3} \mathrm{O}_{3} \mathrm{H}_{3}$ and $* \mathrm{H}$ represent the $\mathrm{EC}\left(\mathrm{C}_{3} \mathrm{O}_{3} \mathrm{H}_{4}\right)$ decomposition products adsorbed on the surface of the oxides $(\mathrm{O}-\mathrm{M}-\mathrm{O})$. The newly formed $\mathrm{C}-\mathrm{O}$ bond with the lattice oxygen replaces the broken $\mathrm{C}-\mathrm{H}$ bond $\left(d\left(\mathrm{C}-\mathrm{O}_{\mathrm{ox}}\right)=1.38 \AA\right.$, where $\mathrm{O}_{\text {ox }}$ indicates a surface oxygen atom) while the hydrogen abstracted from EC forms a hydroxyl group at a surface oxygen site. Remarkably, a considerable amount of electrons $(\geq 1)$ were transferred to the oxide surface associated with this EC dissociation configuration, which reduces two transition metal ions from $M^{n+}$ to $M^{(n-1)+}$.

This finding is supported by the comparison of the charge density difference $(\Delta \rho=\rho(* \mathrm{EC})-\rho(\mathrm{EC})-\rho(*)$, where $\rho$ is the charge density of EC adsorbed on the surface (*EC), EC in the gas phase (EC), and the bare oxide surface $(*))$, spin density maps, and density of states of electrophilic attack and dissociated configurations (Figures 3c,d and S3-S6). While for the electrophilic attack only some charge redistribution takes place on the Co ion coordinated to the molecule (Figures $3 \mathrm{c}$ and S6), in the dissociated configuration a clear depletion of electron density is observed on the EC fragments (Figure 3d), while an accumulation of spin density is detected on two Co ions (Figure S3), indicating a $\mathrm{Co}^{3+} \rightarrow \mathrm{Co}^{2+}$ transition. By contrast, EC dissociation with the extraction of the $\mathrm{O}_{\text {ox }}$ atom from the surface, leaving behind an oxygen vacancy (Figure $1 \mathrm{~d})$, causes ring opening and a rearrangement of the molecule which coordinates with a Co ion $\left(d\left(\mathrm{Co}-\mathrm{O}_{\mathrm{EC}}\right)=1.97 \AA\right)$. Despite a considerable electron transfer to the surface, EC dissociation with the formation of oxygen vacancy was energetically less favorable than EC dissociation without oxygen vacancy, indicating a relatively high cost for the formation of an oxygen vacancy for fully lithiated $\mathrm{LiCoO}_{2}$. Such EC dissociation described in Figure $1 \mathrm{c}$ and the associated charge transfer are supported by previously reported reduction of $\mathrm{Co}$ ions at the surface of $\mathrm{LiCoO}_{2}$ observed by X-ray absorption spectroscopy (XAS) upon soaking in the electrolyte made of a $\mathrm{LiClO}_{4}$-containing $\mathrm{EC}$ and diethyl carbonate (DEC) mixture. $^{38}$

Effect of Lithium Content in $\mathrm{Li}_{x} \mathrm{CoO}_{2}$ on the Reactivity with EC. We compared the energetics of electrophilic attack (Figure 1b) and EC dissociation (without oxygen vacancy, Figure 1c) on
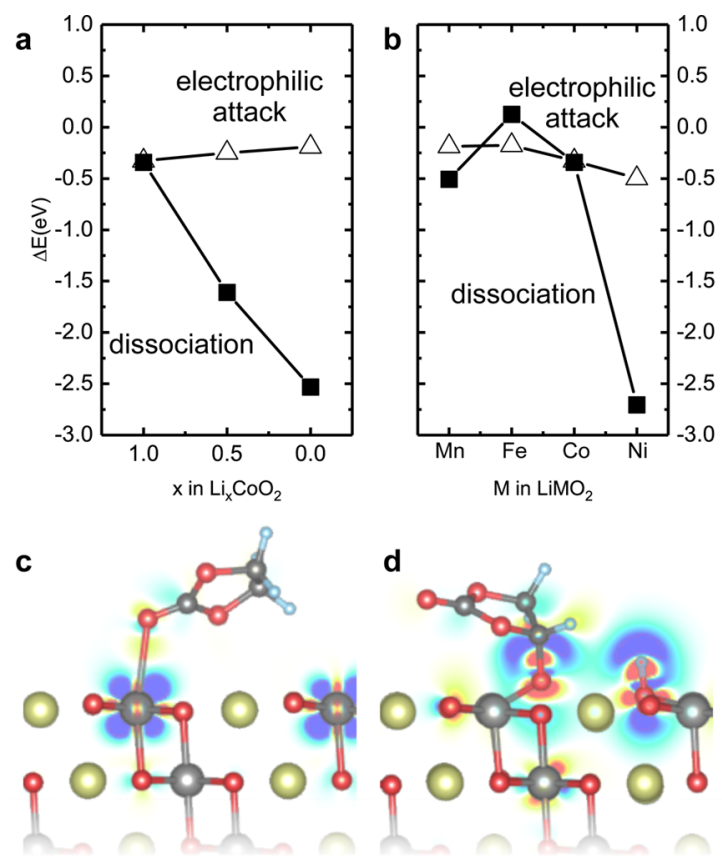

e
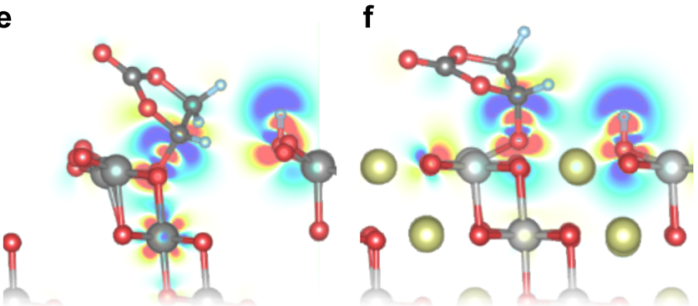

Figure 3. Dependence of the reaction energy $\Delta E$ of electrophilic attack and dissociation configurations on (a) the $\mathrm{Li}$ content in $\mathrm{Li}_{x} \mathrm{CoO}_{2}$ and (b) the transition metal for the adsorption of ethylene carbonate (EC) on the $\mathrm{LiMO}_{2}(10 \overline{1} 4)$ surfaces $(\mathrm{M}=\mathrm{Mn}, \mathrm{Fe}, \mathrm{Co}$, and $\mathrm{Ni})$. (c-f) Charge density difference maps $\Delta \rho$ for (c) electrophilic attack on $\mathrm{LiCoO}_{2}$ (see also Figure $\mathrm{S} 6$ for a different orientation) and dissociation on (d) $\mathrm{LiCoO}_{2},(e) \mathrm{Li}_{x} \mathrm{CoO}_{2}(x=0)$ and (f) $\mathrm{LiNiO}_{2}$. EC adsorption induces some extend of charge redistribution for all configurations. In the dissociated state, we observed accumulation of electron density (in red) on the oxide and depletion of electron density (in blue) on the molecule. The plane of the $2 \mathrm{D}$ maps, oriented in the (100) direction with respect to the surface unit cell and passing through the EC atom coordinated with the surface $\left(\mathrm{O}_{\mathrm{C}}\right.$ for electrophilic attack and $\mathrm{C}$ for dissociation), renders the charge depletion on the molecule more visible, as the reduced transition metal ions are not in the plane.

$\mathrm{Li}_{x} \mathrm{CoO}_{2}(x=1,0.5,0)$, which were found to be exothermic on $\mathrm{LiCoO}_{2}$ in Figure 1. Decreasing lithium content $x$ in $\mathrm{Li}_{x} \mathrm{CoO}_{2}$ $(x=1,0.5,0)$ had negligible changes for the energetics (Figure 3a) and the amounts of charge transferred for the electrophilic attack (Figure S7a). By contrast, EC dissociation became much favorable upon delithiation from $\mathrm{Li}_{x} \mathrm{CoO}_{2}$, reaching a reaction energy $<-2.5 \mathrm{eV}$ for $\mathrm{CoO}_{2}$ (Figure 3a and S9). The amount of charge transferred increased only slightly with decreasing lithium content (Figure 3e and S7a), indicating that the charge transfer is almost completed already at $x=1$ and the surface cannot be reduced further. On the other hand, the energy gain associated with the chemical redox process which accompanies the EC dissociation is strongly enhanced with decreasing the $\mathrm{Li}$ content.

The increased reactivity of the oxide surface with higher degree of delithiation can have a role in the accumulation of 
decomposition products on the EEI layer and the increase of the oligomer/polymer and salt-related $\left(\mathrm{Li}_{x} \mathrm{PF}_{y} \mathrm{O}_{z}\right)$ species, which was observed by XPS on the surface of $\mathrm{Li}_{x} \mathrm{CoO}_{2}{ }^{7,26,39}$ and $\mathrm{Li}_{x} \mathrm{Ni}_{0.8} \mathrm{Co}_{0.2} \mathrm{O}_{2}{ }^{7,25}$ upon charging. Moreover, EC dissociation can play a critical role in the self-discharge mechanism of Li-ion batteries stored in the charged state, as previous studies have shown that the self-discharge involves electrolyte oxidation $^{40}$ and increases with lower lithium content as demonstrated for $\mathrm{LiNi}_{1 / 3} \mathrm{Mn}_{1 / 3} \mathrm{Co}_{1 / 3} \mathrm{O}_{2}$-containing punch cells. ${ }^{41}$

Effect of Transition Metal in $\mathrm{LiMO}_{2}$ on the Reactivity with EC. We further compared the energetics of electrophilic attack and EC dissociation on $\mathrm{LiMO}_{2}(\mathrm{M}=\mathrm{Mn}, \mathrm{Fe}, \mathrm{Co}$, and $\mathrm{Ni})$. The electrophilic attack reaction was weakly exothermic $(-0.5 \mathrm{eV}<$ $\Delta E<0 \mathrm{eV}$ ) and similar for all $\mathrm{LiMO}_{2}$ considered, indicating similar reactivity of $\mathrm{M}^{3+}$ ions with EC, as shown in Figure 3b. The amounts of charge transferred for the electrophilic attack remains small regardless of transition metal ions (Figure S7b). By contrast, the reaction energy of EC dissociation is strongly dependent on $\mathrm{M}^{3+}$ ions, ranging from endothermic for $\mathrm{LiFeO}_{2}$ and weakly exothermic for $\mathrm{LiMnO}_{2}$ and $\mathrm{LiCoO}_{2}$, to strongly exothermic for $\mathrm{LiNiO}_{2}$. On the other hand, the charge transfer is almost unchanged (Figures $3 \mathrm{f}$ and S7b) along the series, indicating that not the amount but the energy gain associated with the charge transfer renders the dissociation more favorable for $\mathrm{LiNiO}_{2}$. Interestingly, Ni-rich $\mathrm{LiNi}_{x} \mathrm{Mn}_{y} \mathrm{Co}_{1-x-y} \mathrm{O}_{2}$ layer materials display higher reactivity and faster aging compared to NMC materials with lower Ni-content, ${ }^{42}$ as also proved by the improved capacity retention and lower impedance of concentration-gradient $\mathrm{NMC}$, where the $\mathrm{Ni}$ content is reduced from the bulk ( $\mathrm{LiNi}_{0.8} \mathrm{Mn}_{0.1} \mathrm{Co}_{0.1} \mathrm{O}_{2}$ ) to the surface of electrode particles. ${ }^{43,44}$ The detrimental effect of Ni-rich phases at the electrode surface can be attributed to the formation of parasitic reaction products associated with the proposed EC dissociation.

A similar drastic decrease of the reaction energy for $\mathrm{LiNiO}_{2}$ is observed for the dissociation accompanied by the formation of an oxygen vacancy, which also causes a reduction of interfacial transition metal ions, while the nucleophilic attack configuration is less affected by the transition metal in $\mathrm{LiMO}_{2}$ (Figure S8).

Our results agree with previous theoretical studies ${ }^{30-33}$ reporting favorable EC dissociation on oxide surfaces. On spinel $\mathrm{Li}_{0.6} \mathrm{Mn}_{2} \mathrm{O}_{4}(100)$ the dissociation with the formation of an oxygen vacancy reduces the total energy by $2.1 \mathrm{eV}$ compared to the physisorbed configuration. ${ }^{30}$ Interestingly, the stability of the dissociated configuration was found to depend on the surface orientation, and to be energetically unfavorable on $\mathrm{Li}_{0.67} \mathrm{Mn}_{2} \mathrm{O}_{4}(111)$, where the physisorbed (electrophyplic attack) configuration is particularly stable $(-1.1 \mathrm{eV}$, including van der Waals corrections). On the other hand, by decreasing the lithium content in $\mathrm{Li}_{x} \mathrm{Mn}_{2} \mathrm{O}_{4}(111)(x=1,0.83,0.67)$, the barrier for $\mathrm{H}$ transfer becomes smaller and the stability of the ring-opened configuration following the dissociation increases, with an energy gain of $2 \mathrm{eV}$ for $\mathrm{Li}_{0.67} \mathrm{Mn}_{2} \mathrm{O}_{4} \cdot{ }^{32} \mathrm{On}$ $\mathrm{Li}_{x} \mathrm{Ni}_{0.5} \mathrm{Mn}_{1.5} \mathrm{O}_{4}(100)(x=0)$ the transfer of two $\mathrm{H}$ to the surface was observed for EC. ${ }^{33}$ More recently, the evolution of the physisorbed (electrophilic attack) into the nucleophilic attack at carbonyl carbon configuration was studied on $\mathrm{LiNi}_{0.5} \mathrm{Mn}_{0.3} \mathrm{Co}_{0.2} \mathrm{O}_{2}$, where the nucleophilic attack configuration was found to be about $0.1 \mathrm{eV}$ more stable. Interestingly, a similar energy gain was found after a follow-up ring opening reaction. ${ }^{31}$ These studies indicate that the reaction mechanisms investigated here initiate the solvent degradation, which can then proceed in subsequent reactions.

We further show that the reaction energy $\Delta E$ of $\mathrm{EC}$ dissociation (Figure 1c) decreases as the Fermi level moves closer to the $\mathrm{O} 2 p$ band center computed from DFT, as shown in Figure 4. Late transition metal $\mathrm{LiMO}_{2}$ oxides and delithiated
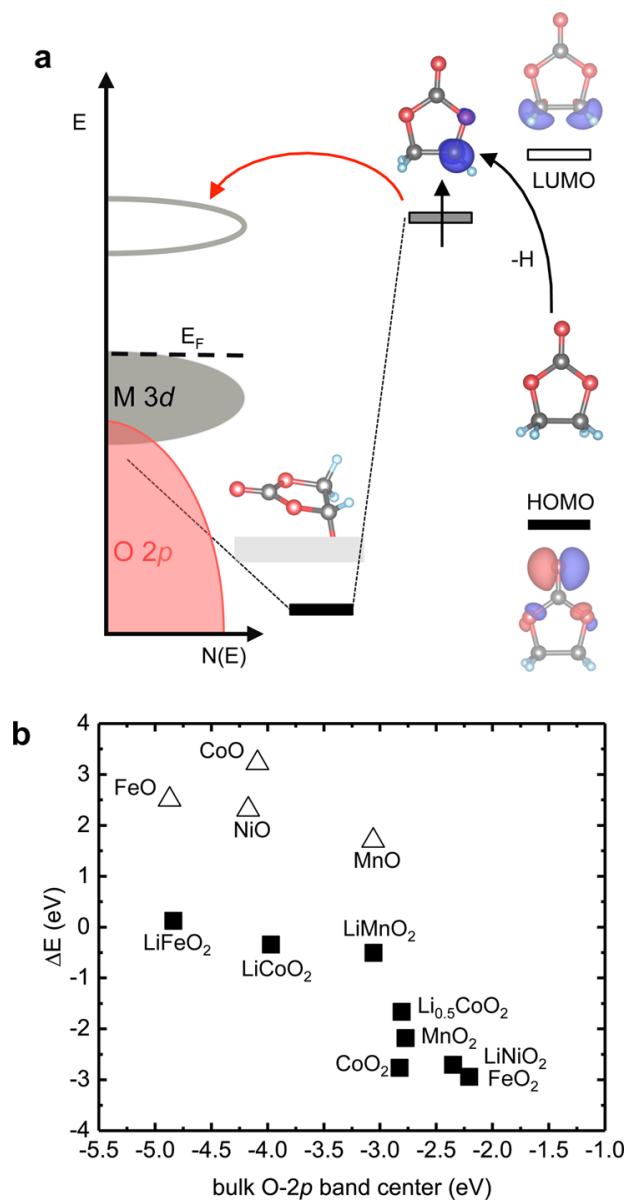

Figure 4. Dependence of the reaction energy $\Delta E$ of EC dissociation on the oxide electronic properties. (a) Schematic representation of the oxide density of states showing the position of the $\mathrm{O} 2 p$ and $\mathrm{M} 3 d$ states relative to the molecular levels for EC (right) and dehydrogenated EC radical interacting with the oxide surface. On the latter, the transfer of the radical unpaired electron to the unoccupied metal $3 d$ states from the HOMO and the formation of a covalent bond between the carbon atom and a surface oxygen are also shown. (b) Energetics of the dissociated configuration as a function of the $\mathrm{O} 2 p$ band center for the adsorption of ethylene carbonate (EC) on the $\mathrm{MO}(100)$ surface $(\mathrm{M}=\mathrm{Mn}, \mathrm{Fe}, \mathrm{Co}$ and $\mathrm{Ni})$ and $\mathrm{Li}_{x} \mathrm{MO}_{2}(10 \overline{1} 4)$ surface $(\mathrm{M}=\mathrm{Mn}, \mathrm{Fe}, \mathrm{Co}$, and $\mathrm{Ni} ; x=1,0.5,0)$.

$\mathrm{Li}_{x} \mathrm{MO}_{2}$, with the Fermi level closer to the oxygen states, have surfaces more prone to be reduced by EC dissociation reaction. On the other hand, $\mathrm{MO}$ oxides with $\mathrm{M}^{2+}$ ions that could not be further reduced were found thermodynamically unfavorable for EC dissociation (Figure 4). The energetics of oxide surface reduction associated with EC dissociation can play a critical role in understanding the formation of reduced oxides such as spinel and rock-salt phases on the surfaces of layered compounds, observed, for instance, on $\mathrm{Li}_{x} \mathrm{Ni}_{0.8} \mathrm{Co}_{0.2} \mathrm{O}_{2},{ }_{45}$ $\mathrm{Li}_{x} \mathrm{Ni}_{1 / 3} \mathrm{Mn}_{1 / 3} \mathrm{Co}_{1 / 3} \mathrm{O}_{2},{ }^{46} \mathrm{Li}_{x} \mathrm{Ni}_{0.4} \mathrm{Mn}_{0.4} \mathrm{Co}_{0.18} \mathrm{Ti}_{0.02} \mathrm{O}_{2}$, ${ }^{47}$ and $\mathrm{Li}_{x} \mathrm{Ni}_{0.8} \mathrm{Co}_{0.15} \mathrm{Al}_{0.05} \mathrm{O}_{2}{ }^{48}$ by transmission electron microscopy (TEM) upon soaking in the electrolyte for long time or cycling. 
The reactivity trend for EC dissociation in Figure 4 is consistent with the higher tendency of Ni-rich NMC materials to formation of reduced rocksalt interfacial layers. ${ }^{42,45,49}$ The formation of the rock-salt layer, experimentally observed by TEM, is then expected to block the dissociation accompanied by solvent oxidation; however, we cannot exclude that other reaction mechanisms ${ }^{31,34}$ can be at play at the surface of these oxides.

We show that chemical oxidation of carbonate solvents such as $\mathrm{EC}$ on layered cobalt or nickel $\mathrm{Li}_{x} \mathrm{MO}_{2}$ oxides is thermodynamically favorable, with a concomitant dissociation involving proton transfer and reduction of the interfacial transition metal ions. This mechanism can initiate in soaked and charged oxide electrodes, where the driving force for the reaction increases with lowered Fermi level relative to the $\mathrm{O} 2 p$ band center associated with less lithium content or replacement of cobalt by nickel. The dissociation of carbonate solvents like EC on oxide surfaces can initiate electrolyte decomposition, where the surface intermediates from this dissociation mechanism can further react and lead to the formation of EEI products. Despite being beyond the focus of this work, we discuss possible routes by which EC dissociation can have a role in the salt anion and electrolyte decomposition. For example, the dissociation reaction, which becomes more favorable upon charging, can increase the electrolyte acidity by reacting with the salt and forming $\mathrm{HF}$ in $\mathrm{LiPF}_{6}$-containing electrolytes. ${ }^{22}$ The presence of $\mathrm{HF}$ is considered to be the prerequisite for the formation of $\mathrm{LiF}$, through acid-base reactions with the oxide surface, ${ }^{50}$ which is shown to be increasingly present in the EEI layer of $\mathrm{LiCoO}_{2}$ as it charges from 4.0 to $4.4 \mathrm{~V}$ voltage. ${ }^{22}$ This reaction also produces water, which reacts with $\mathrm{LiPF}_{6}$ forming more $\mathrm{HF}$ or with $\mathrm{PF}_{5}$ formed by $\mathrm{LiPF}_{6}$ thermal decomposition following the reaction $\mathrm{H}_{2} \mathrm{O}+\mathrm{PF}_{5} \rightarrow \mathrm{PF}_{3} \mathrm{O}+2 \mathrm{HF}^{20}$ Surface hydroxyl groups could also produce water or directly attack $\mathrm{PF}_{5}$ or $\mathrm{PF}_{6}$ anions to form $\mathrm{P}-\mathrm{F}-\mathrm{O}$-containing species, ${ }^{51-54}$ which have been observed in the EEI of $\mathrm{Li}_{x} \mathrm{Mn}_{2} \mathrm{O}_{4}, \mathrm{Li}_{x} \mathrm{CoO}_{2}$, and $\mathrm{Li}_{x} \mathrm{Ni}_{0.8} \mathrm{Co}_{0.2} \mathrm{O}_{2}{ }^{23,25,26}$ Moreover, the $\mathrm{EC}$ fragment from the dissociation mechanism could further decompose, evolving into $\mathrm{CO}_{2}$ or $\mathrm{CO}$ and producing protic species that can migrate to the negative electrode, where they can be reduced to $\mathrm{H}_{2}$. The hypothesis is supported by recent DEMS measurements that show that the amount of hydrogen detected increases with increasing charging voltage, which originates from protic species produced at the positive $\mathrm{LiNi}_{1 / 3} \mathrm{Mn}_{1 / 3} \mathrm{Co}_{1 / 3} \mathrm{O}_{2}$ electrode. ${ }^{55}$ Elucidating molecular details of possible (electro)chemical processes responsible for electrolyte decomposition and the formation of EEI layers on oxide surfaces requires further combined computational and experimental studies.

Here we report that EC dissociation is favorable on oxide surfaces and that the stability of the dissociated state strongly depends on the oxide material. The dissociation results in hydroxylation of the oxide surface and the reduction of interfacial transition metal ions. The tendency of EC to dissociate is strongly material dependent and in particular increases when by changing from early to late transition metal in the periodic table or by lowering the lithium content, both effects resulting in a downward shift of the Fermi level into the oxygen p-band, which can then be used as a descriptor of the oxide reactivity toward the electrolyte. These results can explain the formation of interfacial reduced phases and the higher reactivity of NMC materials with increased Ni content. ${ }^{43-49}$ The EC dissociation mechanism can also have a role in the salt anion decomposition and in the formation of protic species, which evolve into $\mathrm{H}_{2}$ when discharged at the negative electrode.

\section{COMPUTATIONAL METHODS}

Period plane wave density functional theory (DFT) calculations were performed to study the bulk properties and EC adsorption on oxide surfaces. We used PBE functional ${ }^{56}$ as implemented in the Vienna Ab Initio Simulation Package (VASP) code, ${ }^{57,58}$ and Projector Augmented Wave (PAW) for the description of the core-electron interaction, and the plane wave cutoff was set to $450 \mathrm{eV}$. The DFT+U approach was used, ${ }^{59,60}$ where a $U_{\text {eff }}=U$ - $J$ was added on the transition metal $d$ states with $U_{\text {eff }}$ optimized by fitting the formation enthalpies of oxides $\left(U_{\text {eff }}=\right.$ 4.0, 4.0, 3.3, and $6.4 \mathrm{eV}$ for $\mathrm{Mn}, \mathrm{Fe}, \mathrm{Co}$, and $\mathrm{Ni}) .{ }^{61,62}$ The layered structure with space group $R \overline{3} m$ was used for all $\mathrm{LiMO}_{2}$ in this work. We note that, even though the structure can be metastable for some of the materials or compositions, the use of the same structure allows for a direct comparison of the different oxide chemistries. The reciprocal space of the bulk primitive unit cells of $\mathrm{LiMO}_{2}$ and $\mathrm{MO}$ oxides was sampled with $9 \times 9 \times 9 \mathrm{k}$-points mesh. A ferromagnetic ordering was used for all oxides in order to have a consistent and tractable set of magnetic structures. ${ }^{62}$ The (1014) surface of $\mathrm{LiCoO}_{2}$ was shown to have the lowest surface energy among the nonpolar surfaces, ${ }^{37}$ being characterized by a minimal coordination loss of Co ions (from 6-fold in the bulk to 5-fold on the surface), and exposes the $\mathrm{Li}$ intercalation channels. We thus choose this surface for the study of the interaction of $\mathrm{EC}$ with the $\mathrm{Li}_{x} \mathrm{MO}_{2}$ surfaces $(\mathrm{M}=\mathrm{Mn}, \mathrm{Fe}, \mathrm{Co}$ and $\mathrm{Ni} ; x=1,0.5,0)$. The $(001)$ surface was used for the rock-salt $\mathrm{MO}$ oxides $(\mathrm{M}=\mathrm{Mn}, \mathrm{Fe}, \mathrm{Co}$ and $\mathrm{Ni}$ ). The surfaces were modeled with five and six oxide layers for $\mathrm{LiMnO}_{2}$ and $\mathrm{MO}$, respectively, separated by at least $13 \AA$ and a dipole correction was applied in order to eliminate spurious interactions across the periodic boundary along the direction perpendicular to the surface. The three bottom atomic layers were kept fixed at the bulk positions, whereas the surface layers and the adsorbate atomic positions were allowed to fully relax. To avoid lateral interactions between adsorbates, $(4 \times 2)$ and $(4 \times 4)$ surface supercells were used for layered $\mathrm{Li}_{x} \mathrm{MO}_{2}$ and rock-salt oxides, respectively. Due to the large size of the unit cell, the reciprocal space was sampled at the gamma point only. The Bader decomposition method was used for the estimation of charge tranfer. ${ }^{63,64}$ Additional computational details and convergence tests can be found in the Supporting Information.

\section{ASSOCIATED CONTENT}

\section{S Supporting Information}

The Supporting Information is available free of charge on the ACS Publications website at DOI: 10.1021/acs.jpclett.7b01655.

Additional computational details, additional data on structures, reaction energies, charge transfer, spin density and density of states (PDF)

\section{AUTHOR INFORMATION}

\section{Corresponding Authors}

*E-mail: lgiordan@mit.edu (L.G.).

*E-mail: shaohorn@mit.edu (Y.S.-H.).

\section{ORCID $\odot$}

Yang Shao-Horn: 0000-0001-8714-2121 


\section{Notes}

The authors declare no competing financial interest.

\section{ACKNOWLEDGMENTS}

The research was supported by BMW. This research used resources of the National Energy Research Scientific Computing Center, a DOE Office of Science User Facility supported by the Office of Science of the U.S. Department of Energy under Contract No. DE-AC02-05CH11231. This work also used resources of the Extreme Science and Engineering Discovery Environment (XSEDE), ${ }^{65}$ which is supported by National Science Foundation grant number ACI-1548562.

\section{REFERENCES}

(1) Goodenough, J. B.; Park, K.-S. The Li-Ion Rechargeable Battery: A Perspective. J. Am. Chem. Soc. 2013, 135, 1167-1176.

(2) Tarascon, J.-M.; Armand, M. Issues and Challenges Facing Rechargeable Lithium Batteries. Nature 2001, 414, 359-367.

(3) Etacheri, V.; Marom, R.; Elazari, R.; Salitra, G.; Aurbach, D. Challenges in the Development of Advanced Li-Ion Batteries: A Review. Energy Environ. Sci. 2011, 4, 3243.

(4) $\mathrm{Xu}, \mathrm{K}$. Nonaqueous Liquid Electrolytes for Lithium-Based Rechargeable Batteries. Chem. Rev. 2004, 104, 4303-4418.

(5) Leung, K. Two-Electron Reduction of Ethylene Carbonate: A Quantum Chemistry Re-Examination of Mechanisms. Chem. Phys. Lett. 2013, 568-569, 1-8.

(6) Vollmer, J. M.; Curtiss, L. A.; Vissers, D. R.; Amine, K. Reduction Mechanisms of Ethylene, Propylene, and Vinylethylene Carbonates. J. Electrochem. Soc. 2004, 151, A178.

(7) Gauthier, M.; Carney, T. J.; Grimaud, A.; Giordano, L.; Pour, N.; Chang, H.-H.; Fenning, D. P.; Lux, S. F.; Paschos, O.; Bauer, C.; et al. Electrode-Electrolyte Interface in Li-Ion Batteries: Current Understanding and New Insights. J. Phys. Chem. Lett. 2015, 6, 4653-4672.

(8) Aurbach, D.; Markovsky, B.; Shechter, A.; Ein-Eli, Y.; Cohen, H. A Comparative Study of Synthetic Graphite and Li Electrodes in Electrolyte Solutions Based on Ethylene Carbonate-Dimethyl Carbonate Mixtures. J. Electrochem. Soc. 1996, 143, 3809-3820.

(9) Eshkenazi, V.; Peled, E.; Burstein, L.; Golodnitsky, D. XPS Analysis of the SEI Formed on Carbonaceous Materials. Solid State Ionics 2004, 170, 83-91.

(10) Aurbach, D.; Markovsky, B.; Weissman, I.; Levi, E.; Ein-Eli, Y. On the Correlation between Surface Chemistry and Performance of Graphite Negative Electrodes for Li Ion Batteries. Electrochim. Acta 1999, 45, 67-86.

(11) Jeong, S.-K.; Inaba, M.; Iriyama, Y.; Abe, T.; Ogumi, Z. AFM Study of Surface Film Formation on a Composite Graphite Electrode in Lithium-Ion Batteries. J. Power Sources 2003, 119-121, 555-560.

(12) Zhang, X.; Pugh, J. K.; Ross, P. N. Computation of Thermodynamic Oxidation Potentials of Organic Solvents Using Density Functional Theory. J. Electrochem. Soc. 2001, 148, E183E188.

(13) Xing, L.; Borodin, O.; Smith, G. D.; Li, W. Density Functional Theory Study of the Role of Anions on the Oxidative Decomposition Reaction of Propylene Carbonate. J. Phys. Chem. A 2011, 115, 1389613905.

(14) Borodin, O.; Behl, W.; Jow, T. R. Oxidative Stability and Initial Decomposition Reactions of Carbonate, Sulfone, and Alkyl PhosphateBased Electrolytes. J. Phys. Chem. C 2013, 117, 8661-8682.

(15) Tobishima, S.; Okada, T. Lithium Cycling Efficiency and Conductivity for High Dielectric Solvent/Low Viscosity Solvent Mixed Systems. Electrochim. Acta 1985, 30, 1715-1722.

(16) Goodenough, J. B.; Kim, Y. Challenges for Rechargeable Li Batteries. Chem. Mater. 2010, 22, 587-603.

(17) Andre, D.; Kim, S.-J.; Lamp, P.; Lux, S. F.; Maglia, F.; Paschos, O.; Stiaszny, B. Future Generations of Cathode Materials: An Automotive Industry Perspective. J. Mater. Chem. A 2015, 3, 67096732 .
(18) Xu, K.; Ding, S. P.; Jow, T. R. Toward Reliable Values of Electrochemical Stability Limits for Electrolytes. J. Electrochem. Soc. 1999, 146, 4172-4178.

(19) Aurbach, D. Review of Selected Electrode-solution Interactions Which Determine the Performance of $\mathrm{Li}$ and Li Ion Batteries. J. Power Sources 2000, 89, 206-218.

(20) Aurbach, D.; Markovsky, B.; Salitra, G.; Markevich, E.; Talyossef, Y.; Koltypin, M.; Nazar, L.; Ellis, B.; Kovacheva, D. Review on Electrode-Electrolyte Solution Interactions, Related to Cathode Materials for Li-Ion Batteries. J. Power Sources 2007, 165, 491-499.

(21) Thomas, M.; Bruce, P. G.; Goodenough, J. B. AC Impedance Analysis of Polycrystalline Insertion Electrodes: Application to Li1- X CoO2. J. Electrochem. Soc. 1985, 132, 1521-1528.

(22) Dedryvère, R.; Martinez, H.; Leroy, S.; Lemordant, D.; Bonhomme, F.; Biensan, P.; Gonbeau, D. Surface Film Formation on Electrodes in a $\mathrm{LiCoO}_{2} /$ Graphite Cell: A Step by Step XPS Study. J. Power Sources 2007, 174, 462-468.

(23) Eriksson, T.; Andersson, A. M.; Bishop, A. G.; Gejke, C.; Gustafsson, T.; Thomas, J. O. Surface Analysis of $\mathrm{LiMn}_{2} \mathrm{O}_{4}$ Electrodes in Carbonate-Based Electrolytes. J. Electrochem. Soc. 2002, 149, A69.

(24) Eriksson, T.; Andersson, A. M.; Gejke, C.; Gustafsson, T.; Thomas, J. O. Influence of Temperature on the Interface Chemistry of $\mathrm{Li}_{\mathrm{x}} \mathrm{Mn}_{2} \mathrm{O}_{4}$ Electrodes. Langmuir 2002, 18, 3609-3619.

(25) Andersson, A. M.; Abraham, D. P.; Haasch, R.; MacLaren, S.; Liu, J.; Amine, K. Surface Characterization of Electrodes from High Power Lithium-Ion Batteries. J. Electrochem. Soc. 2002, 149, A1358.

(26) Lu, Y.-C.; Mansour, A. N.; Yabuuchi, N.; Shao-Horn, Y. Probing the Origin of Enhanced Stability of "AlPO" Nanoparticle Coated $\mathrm{LiCoO}_{2}$ during Cycling to High Voltages: Combined XRD and XPS Studies. Chem. Mater. 2009, 21, 4408-4424.

(27) Aurbach, D.; Gamolsky, K.; Markovsky, B.; Salitra, G.; Gofer, Y.; Heider, U.; Oesten, R.; Schmidt, M. The Study of Surface Phenomena Related to Electrochemical Lithium Intercalation into $\mathrm{Li}_{\mathrm{X}} \mathrm{MO}_{\mathrm{Y}}$ Host Materials $(\mathrm{M}=\mathrm{Ni}, \mathrm{Mn})$. J. Electrochem. Soc. 2000, 147, 1322-1331.

(28) Levi, M. D.; Salitra, G.; Markovsky, B.; Teller, H.; Aurbach, D.; Heider, U.; Heider, L. Solid-State Electrochemical Kinetics of Li-Ion Intercalation into $\mathrm{Li}_{1-\mathrm{X}} \mathrm{CoO}_{2}$ : Simultaneous Application of Electroanalytical Techniques SSCV, PITT, and EIS. J. Electrochem. Soc. 1999, 146, 1279-1289.

(29) Imhof, R.; Novák, P. Oxidative Electrolyte Solvent Degradation in Lithium-Ion Batteries: An In Situ Differential Electrochemical Mass Spectrometry Investigation. J. Electrochem. Soc. 1999, 146, 1702-1706.

(30) Leung, K. First-Principles Modeling of the Initial Stages of Organic Solvent Decomposition on $\mathrm{Li}_{\mathrm{x}} \mathrm{Mn}_{2} \mathrm{O}_{4}(100)$ Surfaces. J. Phys. Chem. C 2012, 116, 9852-9861.

(31) Xu, S.; Luo, G.; Jacobs, R.; Fang, S.; Mahanthappa, M. K.; Hamers, R. J.; Morgan, D. Ab Initio Modeling of Electrolyte Molecule Ethylene Carbonate Decomposition Reaction on $\mathrm{Li}(\mathrm{Ni}, \mathrm{Mn}, \mathrm{Co}) \mathrm{O}_{2}$ Cathode Surface. ACS Appl. Mater. Interfaces 2017, 9, 20545-20553.

(32) Kumar, N.; Leung, K.; Siegel, D. J. Crystal Surface and State of Charge Dependencies of Electrolyte Decomposition on $\mathrm{LiMn}_{2} \mathrm{O}_{4}$ Cathode. J. Electrochem. Soc. 2014, 161, E3059-E3065.

(33) Borodin, O.; Olguin, M.; Spear, C. E.; Leiter, K. W.; Knap, J. Towards High Throughput Screening of Electrochemical Stability of Battery Electrolytes. Nanotechnology 2015, 26, 354003.

(34) Tebbe, J. L.; Fuerst, T. F.; Musgrave, C. B. Degradation of Ethylene Carbonate Electrolytes of Lithium Ion Batteries via Ring Opening Activated by $\mathrm{LiCoO}_{2}$ Cathode Surfaces and Electrolyte Species. ACS Appl. Mater. Interfaces 2016, 8, 26664-26674.

(35) Grimaud, A.; Hong, W. T.; Shao-Horn, Y.; Tarascon, J.-M. Anionic Redox Processes for Electrochemical Devices. Nat. Mater. 2016, 15, 121-126.

(36) Grimaud, A.; Diaz-Morales, O.; Han, B.; Hong, W. T.; Lee, Y.L.; Giordano, L.; Stoerzinger, K. A.; Koper, M. T. M.; Shao-Horn, Y. Activating Lattice Oxygen Redox Reactions in Metal Oxides to Catalyse Oxygen Evolution. Nat. Chem. 2017, 9, 457-465.

(37) Kramer, D.; Ceder, G. Tailoring the Morphology of $\mathrm{LiCoO}_{2}$ : A First Principles Study. Chem. Mater. 2009, 21, 3799-3809. 
(38) Takamatsu, D.; Koyama, Y.; Orikasa, Y.; Mori, S.; Nakatsutsumi, T.; Hirano, T.; Tanida, H.; Arai, H.; Uchimoto, Y.; Ogumi, Z. First In Situ Observation of the $\mathrm{LiCoO}_{2}$ Electrode/Electrolyte Interface by Total-Reflection X-Ray Absorption Spectroscopy. Angew. Chem., Int. Ed. 2012, 51, 11597-11601.

(39) Quinlan, R. A.; Lu, Y.-C.; Kwabi, D.; Shao-Horn, Y.; Mansour, A. N. XPS Investigation of the Electrolyte Induced Stabilization of $\mathrm{LiCoO}_{2}$ and "AlPO ${ }_{4}$-Coated $\mathrm{LiCoO}_{2}$ Composite Electrodes. J. Electrochem. Soc. 2016, 163, A300-A308.

(40) Tarascon, J. M.; Guyomard, D. New Electrolyte Compositions Stable over the 0 to $5 \mathrm{~V}$ Voltage Range and Compatible with the $\mathrm{Li}_{1+\mathrm{x}} \mathrm{Mn}_{2} \mathrm{O}_{4} /$ Carbon Li-Ion Cells. Solid State Ionics 1994, 69, 293-305.

(41) Xiong, D. J.; Petibon, R.; Nie, M.; Ma, L.; Xia, J.; Dahn, J. R. Interactions between Positive and Negative Electrodes in Li-Ion Cells Operated at High Temperature and High Voltage. J. Electrochem. Soc. 2016, 163, A546-A551.

(42) Jung, R.; Metzger, M.; Maglia, F.; Stinner, C.; Gasteiger, H. A. Oxygen Release and Its Effect on the Cycling Stability of $\mathrm{LiNi}_{\mathrm{x}} \mathrm{Mn}_{\mathrm{y}} \mathrm{Co}_{\mathrm{z}} \mathrm{O}_{2}$ (NMC) Cathode Materials for Li-Ion Batteries. J. Electrochem. Soc. 2017, 164, A1361-A1377.

(43) Sun, Y.-K.; Myung, S.-T.; Park, B.-C.; Prakash, J.; Belharouak, I.; Amine, K. High-Energy Cathode Material for Long-Life and Safe Lithium Batteries. Nat. Mater. 2009, 8, 320-324.

(44) Hua, C.; Du, K.; Tan, C.; Peng, Z.; Cao, Y.; Hu, G. Study of Full Concentration-Gradient $\mathrm{Li}\left(\mathrm{Ni}_{0.8} \mathrm{Co}_{0.1} \mathrm{Mn}_{0.1}\right) \mathrm{O}_{2}$ Cathode Material for Lithium Ion Batteries. J. Alloys Compd. 2014, 614, 264-270.

(45) Abraham, D. P.; Twesten, R. D.; Balasubramanian, M.; Kropf, J.; Fischer, D.; McBreen, J.; Petrov, I.; Amine, K. Microscopy and Spectroscopy of Lithium Nickel Oxide-Based Particles Used in High Power Lithium-Ion Cells. J. Electrochem. Soc. 2003, 150, A1450.

(46) Liu, H.; Bugnet, M.; Tessaro, M. Z.; Harris, K. J.; Dunham, M. J. R.; Jiang, M.; Goward, G. R.; Botton, G. A. Spatially Resolved Surface Valence Gradient and Structural Transformation of Lithium Transition Metal Oxides in Lithium-Ion Batteries. Phys. Chem. Chem. Phys. 2016, 18, 29064-29075.

(47) Lin, F.; Markus, I. M.; Nordlund, D.; Weng, T.-C.; Asta, M. D.; Xin, H. L.; Doeff, M. M. Surface Reconstruction and Chemical Evolution of Stoichiometric Layered Cathode Materials for LithiumIon Batteries. Nat. Commun. 2014, 5, 3529.

(48) Hwang, S.; Chang, W.; Kim, S. M.; Su, D.; Kim, D. H.; Lee, J. Y.; Chung, K. Y.; Stach, E. A. Investigation of Changes in the Surface Structure of $\mathrm{Li}_{\mathrm{X}} \mathrm{Ni}_{0.8} \mathrm{C}_{0.15} \mathrm{Al}_{0.05} \mathrm{O}_{2}$ Cathode Materials Induced by the Initial Charge. Chem. Mater. 2014, 26, 1084-1092.

(49) Jung, S.-K.; Gwon, H.; Hong, J.; Park, K.-Y.; Seo, D.-H.; Kim, H.; Hyun, J.; Yang, W.; Kang, K. Understanding the Degradation Mechanisms of $\mathrm{LiNi}_{0.5} \mathrm{Co}_{0.2} \mathrm{Mn}_{0.3} \mathrm{O}_{2}$ Cathode Material in Lithium Ion Batteries. Adv. Energy Mater. 2014, 4, 1300787.

(50) Aurbach, D.; Markovsky, B.; Rodkin, A.; Levi, E.; Cohen, Y. S.; Kim, H.-J.; Schmidt, M. On the Capacity Fading of $\mathrm{LiCoO}_{2}$ Intercalation Electrodes:: The Effect of Cycling, Storage, Temperature, and Surface Film Forming Additives. Electrochim. Acta 2002, 47, 4291-4306.

(51) Tebbe, J. L.; Holder, A. M.; Musgrave, C. B. Mechanisms of $\mathrm{LiCoO}_{2}$ Cathode Degradation by Reaction with HF and Protection by Thin Oxide Coatings. ACS Appl. Mater. Interfaces 2015, 7, 2426524278 .

(52) Plakhotnyk, A. V.; Ernst, L.; Schmutzler, R. Hydrolysis in the System $\mathrm{LiPF}_{6}$ - propylene Carbonate-dimethyl carbonate- $\mathrm{H}_{2} \mathrm{O}$. J. Fluorine Chem. 2005, 126, 27-31.

(53) Terborg, L.; Nowak, S.; Passerini, S.; Winter, M.; Karst, U.; Haddad, P. R.; Nesterenko, P. N. Ion Chromatographic Determination of Hydrolysis Products of Hexafluorophosphate Salts in Aqueous Solution. Anal. Chim. Acta 2012, 714, 121-126.

(54) Gebala, A. E.; Jones, M. M. The Acid Catalyzed Hydrolysis of Hexafluorophosphate. J. Inorg. Nucl. Chem. 1969, 31, 771-776.

(55) Metzger, M.; Strehle, B.; Solchenbach, S.; Gasteiger, H. A. Origin of $\mathrm{H}_{2}$ Evolution in LIBs: $\mathrm{H}_{2} \mathrm{O}$ Reduction vs. Electrolyte Oxidation. J. Electrochem. Soc. 2016, 163, A798-A809.
(56) Perdew, J. P.; Burke, K.; Ernzerhof, M. Generalized Gradient Approximation Made Simple. Phys. Rev. Lett. 1996, 77, 3865.

(57) Kresse, G.; Hafner, J. Ab. Initio Molecular Dynamics for Liquid Metals. Phys. Rev. B: Condens. Matter Mater. Phys. 1993, 47, 558-561.

(58) Kresse, G.; Furthmüller, J. Efficient Iterative Schemes for Ab Initio Total-Energy Calculations Using a Plane-Wave Basis Set. Phys. Rev. B: Condens. Matter Mater. Phys. 1996, 54, 11169.

(59) Anisimov, V. I.; Aryasetiawan, F.; Lichtenstein, A. I. FirstPrinciples Calculations of the Electronic Structure and Spectra of Strongly Correlated Systems: The LDA + U Method. J. Phys.: Condens. Matter 1997, 9, 767-808.

(60) Dudarev, S. L.; Botton, G. A.; Savrasov, S. Y.; Humphreys, C. J.; Sutton, A. P. Electron-Energy-Loss Spectra and the Structural Stability of Nickel Oxide: An LSDA+ U Study. Phys. Rev. B: Condens. Matter Mater. Phys. 1998, 57, 1505.

(61) Wang, L.; Maxisch, T.; Ceder, G. Oxidation Energies of Transition Metal Oxides within the GGA + U Framework. Phys. Rev. B: Condens. Matter Mater. Phys. 2006, 73, 195107.

(62) Lee, Y.-L.; Kleis, J.; Rossmeisl, J.; Morgan, D. Ab Initio Energetics of $\mathrm{LaBO}_{3}(001)$ ( $\mathrm{B}=\mathrm{Mn}, \mathrm{Fe}, \mathrm{Co}$, and $\mathrm{Ni}$ ) for Solid Oxide Fuel Cell Cathodes. Phys. Rev. B: Condens. Matter Mater. Phys. 2009, 80, 224101.

(63) Bader, R. F. A Quantum Theory of Molecular Structure and Its Applications. Chem. Rev. 1991, 91, 893-928.

(64) Tang, W.; Sanville, E.; Henkelman, G. A Grid-Based Bader Analysis Algorithm without Lattice Bias. J. Phys.: Condens. Matter 2009, 21, 084204.

(65) Towns, J.; et al. XSEDE: Accelerating Scientific Discovery. Comput. Sci. Eng. 2014, 16, 62-74. 